\title{
Uso de la ecografía como apoyo de la técnica de redireccionamiento de la aguja en el dolor de la fístula arteriovenosa durante la hemodiálisis
}

\author{
Antonio López González ${ }^{1}$, Constantino Fernández Rivera², Lorena Díaz Rodríguez, Carmen Ornosa Agra ${ }^{1}$ \\ ${ }^{1}$ Diplomado en Enfermería, ${ }^{2}$ Nefrólogo, Hospital Quirón A Coruña. España
}

\section{Introducción}

Es indudable que el acceso vascular no sólo es uno de los elementos clave para poder llevar a cabo el tratamiento sustitutivo renal con hemodiálisis sino que representa una de las principales causas de morbilidad, hospitalización y coste en los enfermos tratados con esta técnica. La fístula arteriovenosa sigue siendo el acceso vascular de elección. El hecho de que el paciente acuda al menos tres veces por semana para el tratamiento, convierte a la técnica de punción de la fístula en uno de los factores más relevantes que influyen en su supervivencia y, por tanto, en la calidad de vida del paciente ${ }^{1,2}$.

Los problemas relacionados con la técnica incluyen un gran abanico de contratiempos (canalización dificultosa, presiones venosas elevadas, elevada recirculación, bajo flujo, presencia y aspiración de coágulos, hemostasia prolongada, etc.) siendo el dolor un evento muy prevalente ${ }^{3}$. A pesar de que son muchos los estudios de calidad de vida relacionada con la salud que analizan el dolor del paciente en hemodiálisis, en pocas ocasiones se hace referencia al acceso vascular como variable independiente $y$, los que lo hacen, únicamente hacen referencia al dolor crónico o al momento de la punción ${ }^{4}$. Sin embargo, uno de los eventos que mayor ansiedad y disconfort genera al paciente es el dolor producido durante la sesión relacionado con la posición de las agujas de punción.

Por tanto, el objetivo de este estudio es presentar un caso donde se describe el uso de los ultrasonidos para

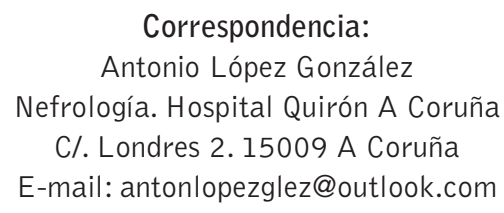

el manejo del dolor de la fistula arteriovenosa durante la sesión de hemodiálisis vinculado al posicionamiento de la aguja en el vaso sanguíneo.

\section{Descripción del caso}

Paciente varón de 53 años, diagnosticado en 1986 de insuficiencia renal crónica estadío $V$ de etiología no filiada (probable intoxicación por plomo), en programa de hemodiálisis a través de fístula arteriovenosa, que presentó episodios recurrentes de dolor del acceso vascular durante las sesiones. Otros antecedentes de interés.

\section{- Antecedentes nefrológicos:}

Trasplante renal de donante cadáver en marzo de 1988, funcionante hasta noviembre de 1997 con pérdida de injerto por rechazo crónico.

Segundo trasplante renal de donante cadáver en agosto de 2002 con disfunción crónica del injerto volviendo a programa de hemodiálisis en 2006.

Tercer trasplante renal en junio de 2014 con infarto renal en julio de 2014, estenosis de la arteria renal en agosto de 2014 con requerimiento de angioplastia.

A estudio por probable microangiopatía trombótica.

Anemia nefrogénica.

Hiperparatiroidismo secundario.

\section{- Antecedentes digestivos:}

Hepatopatía crónica secundaria a VHC.

Hepatitis colestásica fibrosante en enero de 2007.

Trasplante hepático en junio de 2014 funcionante con requerimiento de angioplastia por estenosis de la arteria hepática.

Esofagitis por reflujo Grado II.

Gastritis erosiva antral. 


\section{- Otros antecedentes:}

Fístula arteriovenosa radiocefálica en miembro superior izquierdo funcionante (1986).

Tuberculosis antigua.

Episodios recurrentes de gota.

El dolor se producía una vez superada la mitad de la sesión y era descrito como una sensación punzante y ardiente con intensidad EVA 9/10, localizado en las zonas de punción e irradiado a lo largo del trayecto de la fístula hasta el hombro, siendo refractario a analgesia.

No se evidenció relación con hipotensión arterial, desajuste en los parámetros velocidad de bomba y presión venosa, problemas en la canalización o movimiento accidental de la aguja. En la exploración física de la fístula, se observó vena de característica laxa y tortuosa, con tendencia al colapso. No se evidenció signos de flebitis ni ausencia de soplo y thrill en todo el trayecto. Mano bien perfundida, con pulsos radiales y cubitales presentes. El flujo sanguíneo de la fístula, medido con la técnica de termodilución, era de $1200 \mathrm{ml} / \mathrm{min}$ con una recirculación del 3\%.

Después de múltiples manipulaciones inefectivas de la orientación de la aguja, se finalizó la sesión de hemodiálisis y se planteó, para las próximas hemodiálisis, la valoración ecográfica pre-punción para la elección de los puntos de inserción de las agujas. Sin embargo, ante la continuidad de los episodios de dolor, se remitió a cirugía vascular para examen fistulográfico por posible estenosis del acceso. En el estudio se evidenció una adecuada permeabilidad sin observarse estenosis en el trayecto de la vena cefálica y basílica a partir del codo, así como de la vena axilar y subclavia. Además, se observó múltiples zonas de dilatación de la vena cefálica hasta el codo. No se refirieron alteraciones en la anastomosis radiocefálica.

Finalmente, se optó por la monitorización ecográfica del acceso durante el episodio de dolor. Se evidenció que la parte distal de la aguja arterial estaba insertada presionando la pared del vaso (Imagen 1) debido, posiblemente, a un movimiento del brazo de la fístula.

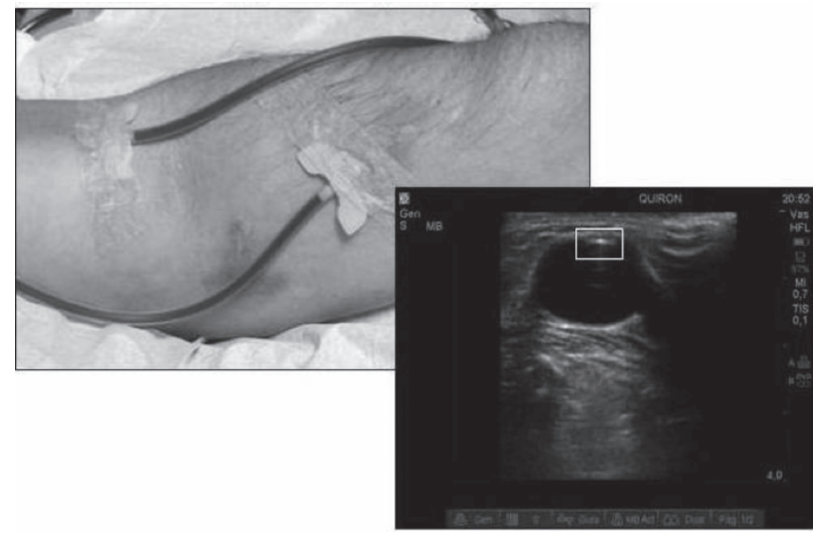

\section{- Imagen 1. Posición Inicial}

Se procedió a la angulación de la aguja guiada con ecógrafo con el fin recolocarla en la luz de la vena. Con una angulación de $35^{\circ}$ (Imagen 2) se observó que la punta de la aguja seguía traccionando la pared.

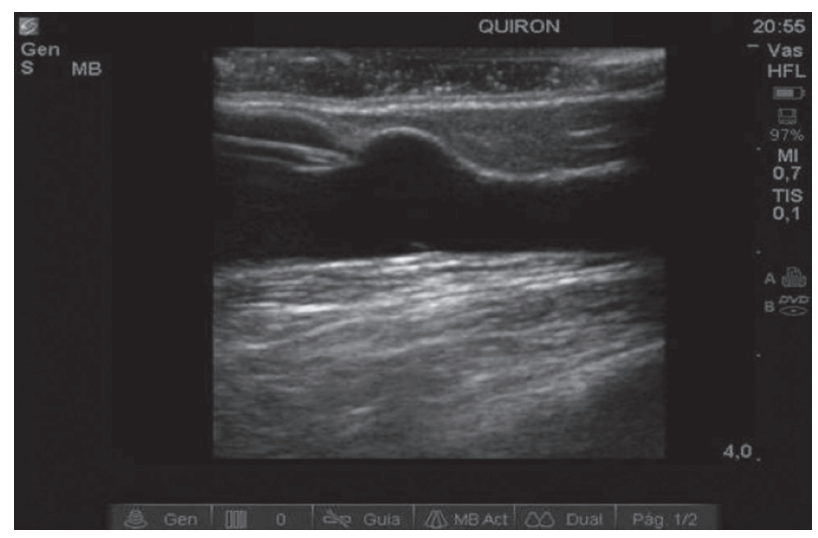

- Imagen 2. Redireccionamiento $35^{\circ}$

Requirió una angulación y fijación de $45^{\circ}$ para poder observar la aguja en la luz de la vena (Imagen 3), momento en el cual el dolor ceso de manera instantánea (Eva 0/10).

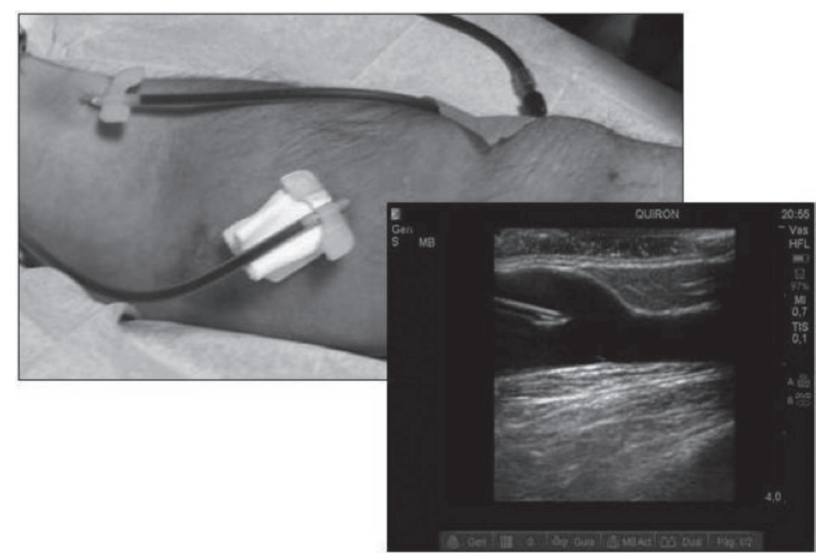

- Imagen 3. Redireccionamiento $45^{\circ}$ 


\section{Discusión}

La ecografía doppler es una herramienta muy importante para la atención al paciente portador de fistula arteriovenosa en hemodiálisis. Es el único método no invasivo que nos aporta información anatómica y hemodinámica al mismo tiempo, permitiéndonos así, un diagnóstico rápido de patología del acceso vascular. Del mismo modo, en accesos dificultosos, el estudio ecográfico nos puede poner de manifiesto, "en tiempo real", una incorrecta posición de la aguja, ayudar en el redireccionamiento de la misma y diagnosticar problemas técnicos durante la realización de la maniobra de punción.

Existen estudios que abordan el manejo del dolor del acceso en el momento de la punción ${ }^{5,6}$. Sin embargo, no hay evidencias publicadas de su manejo durante el período en que las agujas permanecen dentro de la luz del vaso. Este dolor neuropático y lancinante, producido por la presión ejercida por la aguja sobre la "vassa nervorun" (red de fibras nerviosas que inervan el vaso) presente en la pared vascular, se asocia a fistulas cuyas características anatómicas y de maduración dificultan la punción, a movimientos accidentales del miembro donde se localiza la fistula, a una fijación insuficiente de las agujas y a episodios de descenso brusco de la tensión arterial. En la mayoría de los episodios, la solución pasa por un redireccionamiento de la aguja. Tradicionalmente, esta técnica se realiza mediante la observación y palpación de la vena para detectar su profundidad y recorrido. En este caso, también hemos utilizado los ultrasonidos ya que, al proporcionarnos una imagen inmediata, nos permite aumentar el éxito de la técnica evitando demoras, punciones infructuosas, lesiones del vaso, extravasaciones y aumentando la supervivencia del acceso.

En definitiva, la incorporación de la ecografía al entorno de diálisis nos permite tomar decisiones de manera inmediata desde la cabecera del paciente, orientándonos de un modo preciso y seguro para la solución de las complicaciones relacionadas con el manejo de las agujas de diálisis.

\section{Bibliografía}

1. Rodríguez JA, González E, Gutiérrez JM, et al. Guías de acceso vascular en hemodiálisis (Guías S.E.N.). Nefrologia. 2005; 25 (Supl 1):3-97.

2. National Kidney Foundation. KDOQI Clinical Practice Guidelines and Clinical Practice Recommendations for 2006 Updates: Hemodialysis Adequacy, Peritoneal Dialysis Adequacy and Vascular Access. Am J Kidney Dis. 2006; 48(Suppl 1):S1-S322.

3. Rodríguez Calero MA, Hernández Sánchez D, Gutiérrez Navarro MJ, Juan Amer F, Calls Ginesta J, Sánchez Llull J. Evaluación y manejo del dolor intradiálisis. Rev Soc Esp Enferm Nefrol. 2006; 9 (2): 65-70.

4. Pelayo Alonso R, Cobo Sánchez JL, Reyero López M, Sáenz de Buruaga Perea A, Tovar Rincón A, Alonso Nates R. Repercusión del acceso vascular sobre la calidad de vida de los pacientes en tratamiento con hemodiálisis. Rev Soc Esp Enferm Nefrol. 2011; 14 (4): 242-249.

5. Granados Navarrete I, Abril Sabater D, Alcaraz Busqueta F, Mañé Buixo N, Padilla Ruiz J, Real Gatius $J$ et al. Una actuación de enfermería: intentar aliviar el dolor en las punciones de hemodiálisis. Rev Soc Esp Enferm Nefrol. 2005; 8 (3):231-236.

6. Ahis Tomás P, Peris Ambou I, Pérez Baylach CM, Castelló Benavent J. Evaluación del dolor en la punción de una fístula arteriovenosa para hemodiálisis comparando pomada anestésica frente a frío local. Enferm Nefrol. 2014; 17 (1): 11-15. 